\title{
Nanotechnology Innovations and Commercialization-Opportunities, Challenges \& Reasons for Delay
}

\author{
P. Sreeramana Aithal ${ }^{\mathrm{a}^{*}}$, Shubhrajyotsna Aithal ${ }^{\mathrm{b}}$ \\ ${ }^{a}$ Srinivas Institute of Management Studies, Pandeshwar, Mangalore -575 001, India \\ ${ }^{b}$ Dept. of Chemistry, Srinivas School of Engineering, Mukka, Mangalore-574 146. India
}

\begin{abstract}
Innovations in nanotechnology are making a revolution in manufacturing and production, creating new materials and products through novel processes for commercial applications. New products based on nanotechnology with novel characteristics are continued to grow and benefit the society. Being general purpose technology, nanotechnology is expected to support all fields of the society, but some fields like medicine, energy, environmental remediation, robotics, manufacturing, commerce, and space exploration are expected to undergo explosive developments. In this paper, we made a detailed analysis of advantages, benefits, constraints, and disadvantages of progress in nanotechnology for the society and discussed the reason for the failure of estimated timeline for realizing various generations of progress and proposed a modified timeframe for anticipated nanotechnology innovations. Based on the business perspective, we have developed a nanotechnology products/services commercialization model and discussed the opportunities for nanotechnology commercialization. The paper also contains a detailed analysis of common commercialization challenges faced by nanotechnology firms including time lag, the valley of death, lack of infrastructure, lack of a standard for evaluation, bureaucratic delays, the dearth of funding, and lack of trained professionals, brand image, and public support. Finally, we have mentioned how the various corporate business strategies can be used in the successful business of nanotechnology products and services.
\end{abstract}

Index Terms: Commercialisations of nanotech products, Challenges in commercialization of new products, Nanotechnology commercialization model.

(C) 2016 Published by MECS Publisher. Selection and/or peer review under responsibility of the Research Association of Modern Education and Computer Science.

\section{Introduction}

Nanotechnology has the potential to solve problems related to human civilizations pertaining to both basic needs and aspirations for comfort life. The basic needs of human being are food, drinking water, energy, cloth,

\footnotetext{
* Corresponding author. Tel.: +919343348392; fax:+918242426766

E-mail address: psaithal@gmail.com
} 
shelter, health and clean environment. The aspirations for comfort life are realizing the automation in every field, space travel and expanded lifespan and so on. Due to continuous efforts of scientists and engineers during last 30 years, there is a substantial progress in realizing the nanotechnology-based components and products in different areas including agriculture, food product and packaging, purification of water, automobiles, atmospheric cleaning, renewable energy, energy storage, consumer goods, sports equipment, cosmetics, cloth and fabrics, construction materials, shelter, health, information communication technology, high speed manufacturing, space travel, military, sustainable environment, computer \& robotic technology, and even lifespan expansion [1]. Hence it has the potential to solve all social problems like eradication of poverty, a permanent solution to hunger and thirst, social evils like corruption, threats on equality etc. Hence, has the ability to fulfill the characteristics of ideal technology [2]. Even though nanotechnology involves the manipulation of matter on an atomic, molecular, and supramolecular scale, the particular technological goal is of precisely manipulating atoms and molecules for fabrication of macroscale products, also now referred to as molecular nanotechnology. Nanotechnology is evolving towards becoming a general-purpose technology by 2020, encompassing four generations of products with increasing structural and dynamic complexity : (1) passive nanostructure (2) active nanostructures, (3) nanosystems (4) molecular nanosystems. By 2020, the increasing integration of nanoscale science and engineering knowledge and of nanosystems promises mass applications of nanotechnology in industry, medicine, and computing and in better comprehension and conservation of nature. Nanotechnology's rapid development worldwide is supporting this anticipation of its expected progress of transforming the society and future of living beings. However, the slow pace of actual progress against predicted roadmap has to be re-examined and more planned efforts have to be made by country governments and nanotechnology research organizations. In this paper, we analyze the advantages, benefits, constraints, and disadvantages of nanotechnology as an anticipated breakthrough general purpose technology of the twenty-first century. In this paper, based on the possible applications of nanotechnology in many important areas like agriculture, food industry, water purification, renewable energy \& storage, cloth \& fabrics, automobiles, cosmetics, computer technology, consumer goods, medicine \& health, aerospace sector etc. the advantages, benefits, constraints, and disadvantages are listed. By studying the reviews on predictions of the timeline of nanotechnology commercialization, it is found that there is a delay in commercialization of nanotechnology research and hence, the duration of each generation is expanded against the prediction by Roco, 2004 [3]. While studying the reason for the delay from the business perspective, the essential elements for the successful commercialization of a specifically directed nanotechnology include innovative products, market size, market potential, and the current economic scenario. The paper contains a detailed analysis of common challenges faced by nanotechnology firms including Time Lag, Valley of Death, Lack of infrastructure, Lack of standard for evaluation, Bureaucratic delays, Dearth of funding, Lack of trained professionals, Brand image, and Public support.

\section{ABCD Listing of Nanotechnology}

Based on the potential ability of nanotechnology as general purpose technology and its consideration as "anticipated breakthrough technology of $21^{\text {st }}$ century" to solve all human problems and elevate those to highest comfortable solutions, it is essential to know the detailed advantages, benefits, constraints and disadvantages called ABCD listing [4-5] of progress of nanotechnology in the society.

\section{(a). Advantages of Nanotechnology:}

The advantage is the quality of having a superior or more favorable position. It can be any state, circumstance, opportunity, or means specially favorable to success, interest, or any desired end. Some of the important advantages of nanotechnology are:

(1) Nanomaterials are more efficient materials with very useful characteristics in terms of strength, 
lightness, ductility, extremely small size, thermal and electrical conductibility, and water repellency.

(2) Usage of nanomaterials as raw material, machine or equipment reduces the size.

(3) Nanotechnology ideas can be applied and implemented to solve almost any problem ever exist.

(4) Nanotechnology provides a mean to decrease the use of energy and other resources.

(5) Nanotechnology provides a mean to efficient production of energy and other resources.

(6) Nanotechnology is capable of changing the basis of technology of human when it's mature.

(7) By solving basic and specific problems of all ages of people in the society, nanotechnology is able to secure to the economy of the world once it is fully implemented.

(8) Nanotechnology can solve basic problems of the society like nutritious food, clean drinking water.

(9) Nanotechnology provides a mean of renewable green energy production on earth for societies ever growing requirement.

(10) Nanotechnology solves all health related problems by preventing or providing solutions to cure all types of diseases.

(11) Nanotechnology together with biotechnology and molecular engineering supports to regenerate body parts of living beings as well as to slow down aging process. This provides a mean to lifespan expansion of human beings.

(12) Nonmaterial are free from thermal and mechanical stress.

(13) A broad variety of nano-substance classes allows the use of them for any applications.

(14) Nanotechnology allows identical hardware for laboratory design and production, pilot production and for standard market production (no scale up).

(15) No limits in the capacity of production of nanomaterials and nanodevices using molecular engineering.

(16) Further improvement opportunities in information and communication technologies to develop ideal systems.

(17) Improved self-assembled manufacturing methods and systems.

\section{(b). Benefits of Nanotechnology:}

The benefit is the gain obtained by the advantages of nanotechnology to the human being and the entire society. While nanotechnology is still an emerging field, a number of products are currently being produced utilizing nanomaterials. Some of the noted and expected benefits of nanotechnology include:

(1) Quality food products at affordable price.

(2) An abundant amount of portable drinking water for human use and clean water for agricultural and industrial uses.

(3) Cheaper green energy and its storage for all types of energy applications in the society.

(4) Nanotechnology-based health products cures and prevents many types of diseases at low cost including organ regeneration and permanent health solutions lead to sustainable health for every human being.

(5) Cheaper, safe and effective cosmetics, cloth, footwear, sports equipments and many other day-to-day consumables.

(6) Safer, cheaper, technologically advanced, maintenance-free, and emission-free transportation vehicles.

(7) Benefits of lighter, cheaper, high-speed airplanes, spacecraft and space rockets production and even development of light and high capacity satellites using nanotechnology.

(8) Long term benefits of nanotechnology include regular space travel, life span expansion to attain superhuman stage as predicted in science fictions.

(9) The benefit of reduced size, cost and increased speed and bandwidth of electronic communication and computer devices.

\section{(c). Constraints of Nanotechnology:}


A constraint is a limitation or restriction in a system or process or an element and acts as bottleneck from achieving its potential with reference to its goal. Some of the prominent constraints of nanotechnology-based systems in the society are:

(1) Low investments in research and developments in nanotechnology products and services.

(2) Many nanotechnology products are still in laboratory level and failed to commercialize due to organizational unawareness and wrong strategies.

(3) No proper information about the environmental effects of nanomaterials and its impact on human life.

(4) Low awareness on possible general purpose technology, its advantages, and benefits.

(5) Less number of trained human resources available to do research, innovations and to start a new business based on nanotechnology products and services.

(6) Low priority is given by governments of developing countries on research and development of nanotechnology based products and services even though it has more benefits for such countries.

(7) Failure of fulfilling the expected developments as per the nanotechnology roadmap due to low encouragement from Governments, Multinational companies and other firms due to lack of confidence.

\section{(d). Disadvantages of Nanotechnology:}

The disadvantage is a situation or condition which identifies the drawbacks and weakness of a system. The major disadvantages of nanotechnology for its quick commercialization are:

(1) Heavy investment in research and development.

(2) Low supply of skilled manpower and researchers in the field.

(3) Low awareness due to lack of knowledge among the business organizations and entrepreneurs on nanotechnology-based new business opportunities.

(4) Low encouragement by the government, venture capitalists and banking organizations due to lack of awareness.

(5) Fear of health-related side-effects due to nanotechnology products usage.

(6) Expensive in current technology

(7) Nanotechnology innovations require a huge amount of investment and research but still yield a very limited result.

(8) Facing opposition from the culture perspective, activists, and journalists and even within the government due to the fact that some nanomaterials may be toxic to humans.

(9) The replacement of natural products including rubber, cotton, various food grains, coffee, tea etc. by artificially developed products using nanotechnology may imbalance the economy of certain developing countries.

(10) Ecological impacts of the release of nano-wastes into the environment and effect of nano-waste on animal and plant cells are unknown.

Based on the knowledge of advantages, benefits, constraints, and disadvantages, it is possible to predict the applications of nanotechnology in various areas of society accurately. Some of the important applications of nanotechnology are in agriculture, food industry, water purification, renewable energy \& storage, cloth \& fabrics, automobiles, cosmetics, computer technology, consumer goods, medicine \& health and aerospace sector.

\section{Nanotechnology in Social Problems:}

There are high expectations that nanotechnology solves a bunch of social problems from the collapse of birth rate in advanced nations to global warming, and currently incurable illnesses, such as cancer or AIDS. On the 
other hand, the obscurity of the form of future nanotechnology has bred some end-of-the-world scenarios. The most famous one is known as "Grey goo" which is a hypothetical end-of-the-world scenario involving molecular nanotechnology in which out-of-control self-replicating robots consume all matter on Earth while building more of themselves, a scenario known as ecophagy ("eating the environment"). Alternatively, the most dangerous outcome of molecular nanotechnology would be non-replicating weapons which are easier to build.

\section{Failure to Achieve Estimated Timeline of Commercialization - New Proposal}

Timeline for nanotechnology innovations is predicted in various literature as shown in table 1 . The earlier prediction of nanotechnology timeline is given by Roco in the year 2004 and the new prediction based on last 15 years development is also given in Aithal et.al during 2015 [1] is listed in table 1. Based on this new roadmap, we have completed the first generation of passive nanostructures by 2015 and just entered the second generation of active nanostructures which may long last till 2020. The third generation of nanosystems which include assemblies of nanotools work together to achieve a final goal may be completed by the year 2035 and the fourth generation of molecular nanosystems which involves the intelligent design of molecular and atomic devices, leading to unprecedented understanding and control over the basic building blocks of all natural and man-made things by the year 2050. This prediction is made based on present systematic investments on nanotechnology based product innovations by developing countries along with developed countries, and the multinational companies and also by studying the universities efforts worldwide on developing nanotechnology graduates, postgraduates and based on the promises shown by research personnel all over the world and the efforts being done by world top research centres including NASA in the process of creating breakthroughs in nanotechnology. If this prediction goes reality like the development of various generations of computers happened during the end of $20^{\text {th }}$ century, the dream of nanotechnology-based super civilization is going to be a reality after the year 2050 itself.

Table 1. Anticipated Timeline of Nanotechnology Innovations

\begin{tabular}{|c|c|c|c|c|}
\hline $\begin{array}{l}\text { Nanotech } \\
\text { Generation }\end{array}$ & Development & Examples & $\begin{array}{l}\text { First Prediction by } \\
\text { Roco 2004 [3] }\end{array}$ & $\begin{array}{l}\text { Recent Prediction by } \\
\text { Aithal } 2015 \text { [1] }\end{array}$ \\
\hline $\begin{array}{l}\text { First } \\
\text { Generation }\end{array}$ & $\begin{array}{l}\text { Passive Nanostructures } \\
\text { Ex: Coatings, nanoparticles, } \\
\text { nanostructured metals, } \\
\text { polymers, ceramics. }\end{array}$ & $\begin{array}{l}\text { Nanomaterials, including } \\
\text { nanotubes and nanolayers. }\end{array}$ & $2000-2005$ & $2000-2015$ \\
\hline $\begin{array}{l}\text { Second } \\
\text { Generation }\end{array}$ & $\begin{array}{l}\text { Active Nanostructures } \\
\text { Ex: 3D transistors, amplifiers, } \\
\text { targeted drugs, actuators, } \\
\text { adaptive structures. }\end{array}$ & $\begin{array}{l}\text { Change their state during } \\
\text { use, responding in } \\
\text { predictable ways to the } \\
\text { environment. }\end{array}$ & $2005-2010$ & $2015-2020$ \\
\hline $\begin{array}{l}\text { Third } \\
\text { Generation }\end{array}$ & $\begin{array}{l}\text { Nanosystems } \\
\text { Ex: Guided assembling; 3D } \\
\text { networking and new } \\
\text { hierarchical architectures, } \\
\text { robotics. }\end{array}$ & $\begin{array}{l}\text { Assemblies of nanotools } \\
\text { work together to achieve a } \\
\text { final goal. }\end{array}$ & $2010-2015$ & $2020-2035$ \\
\hline $\begin{array}{l}\text { Fourth } \\
\text { Generation }\end{array}$ & $\begin{array}{l}\text { Molecular Nanosystems } \\
\text { Ex: Molecular devices 'by } \\
\text { design', atomic design, Gene } \\
\text { therapy. }\end{array}$ & $\begin{array}{l}\text { Involves the intelligent } \\
\text { design of molecular and } \\
\text { atomic devices, leading to } \\
\text { "unprecedented } \\
\text { understanding and control } \\
\text { over the basic building } \\
\text { blocks of all natural and } \\
\text { man-made things. }\end{array}$ & $2015-2020$ & $2035-2050$ \\
\hline $\begin{array}{l}\text { Fifth } \\
\text { Generation }\end{array}$ & Singularity & $\begin{array}{l}\text { Growth rate in NT } \\
\text { applications become infinite. }\end{array}$ & $2020-2015$ & Beyond 2050 \\
\hline
\end{tabular}




\section{Commercialization of Nanotechnology}

Technology commercialization is the process of converting ideas into products for businesses and consequentially, creating demands for the products and jobs for the people. Commercialization of nanotechnology from research to economically viable product is particularly vulnerable to the "Valley of Death" point of commercialisation graph compared to any other technologies due to the reasons related to a product focus, market engagement, scale up and product development [6]. From a business perspective, the essential elements for the successful commercialization of a specifically directed nanotechnology include innovative products, market size, market potential, and the current economic scenario and accordingly using qualitative data collection instrument namely focus group method [7], we have developed a model for successful nanotechnology commercialization process as shown in fig. 1 which include ten steps to develop standard products/services.

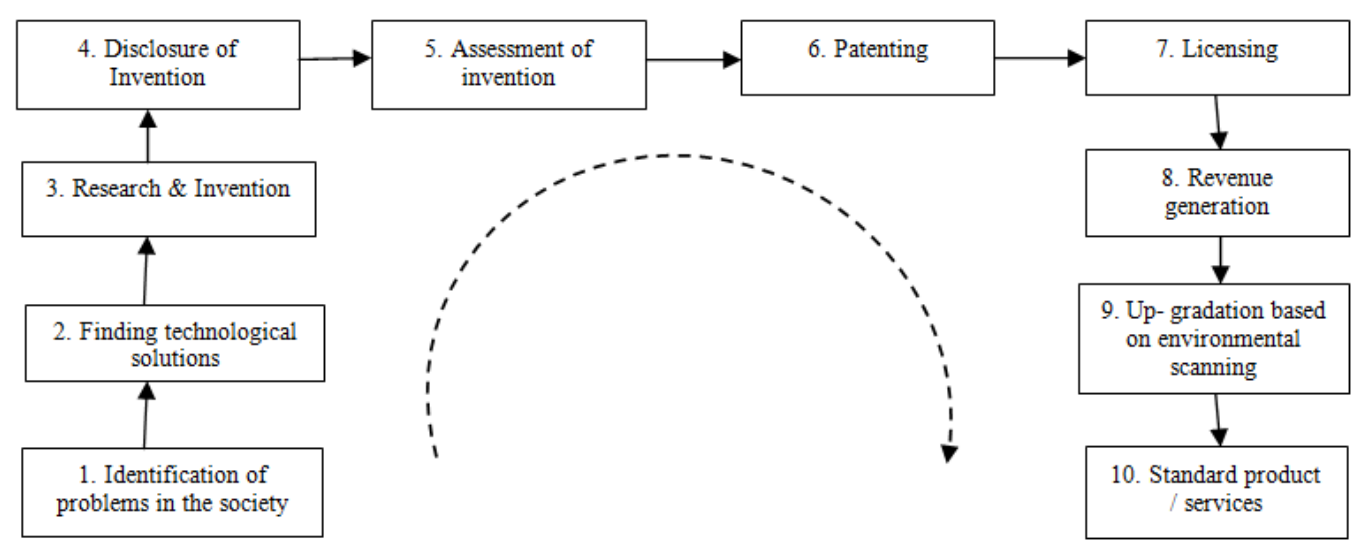

Fig.1. Steps Required in Successful Nanotechnology Commercialization Model.

\section{(a). Steps in Nanotechnology Commercialization Model:}

1. Identification of Problems in the society: When an organization is planning to encash opportunities in nanotechnology-based business, it has to carry out a market survey and has to arrive at the conclusion on which product in which area has better demand, easy to develop, produce and market with low initial investment and sustainability.

2. Finding technological solutions through Ideas \& Concepts: After identifying the possible products based on nanotechnology, the firm should do a technological feasibility study of producing such product with requited features.

3. Research \& Invention - Product development, design, modelling \& simulation: Once the firm understands that identified product is feasible to develop, it has to invest in indigenous research or collaborate with existing research organizations to develop the product.

4. Disclosure of Invention: Soon after the product is developed in R \& D section of the firm, enough publicity should be given through various types of campaigns to create local and global demand.

5. Assessment of invention: Parallelly, the firm should make an assessment of the features of the products, reproducibility of the properties, reliability on the performance etc.

6. Patenting: In order to protect the intellectual property right of the invention, the firm should get protection by applying for a patent on the product/processes.

7. Licensing: Based on the patent right, the firm has to plan its strategy and take the decision to produce the product either directly under its own brand or by licensing to other firms spread globally. 
8. Revenue generation: Through creating demand as well as its pricing strategy the firm has to decide its revenue generation model to realize its objective of maintaining long term profit.

9. Up gradation based on environmental scanning: Based on feedback from the stakeholders, and monitoring its environmental effects, the firm has to continuously upgrade the performance of the product and monitor its quality \& performance.

10. Standard product / services: By standardizing the product/service, the firm can implement and develop technical standards which help to maximize compatibility, interoperability, repeatability, safety, or quality. It can also facilitate commoditization of the product.

Any firm which plans to do business using nanotechnology products/services gets success by following the above steps of our nanotechnology commercialization model.

\section{(b). Opportunities for Nanotechnology Commercialisation:}

1. Huge expectation from the society: By knowing the advantages and benefits of nanotechnology, people are waiting for the breakthrough of nanotechnology products in all areas of the consumer requirements in the society.

2. Opportunity for new innovative product development : Based on substantial advantages and hence expected huge demand for nanotech products, there are almost infinite number of opportunities for new product development in different areas of the society.

3. Opportunity for both small business and mega business players based on their investment capacity : Since nanotechnology products varying from simple cosmetic product to screen infrared rays from skin to artificial food products to self-generating molecular motors, depending on the interest and capability of firm, it can focus a particular type of product so that both small business firms and mega business firms have opportunity in nanotechnology product development and marketing.

4. Opportunity for new product development for entrepreneurs in their existing field itself so that they can use their experience: Being general purpose technology, nanotechnology provides scope for existing firms to upgrade their products/services. Hence, the existing entrepreneurs can plan to improve their products by improving them using nanotechnology features for improved performance.

5. The new discoveries and innovations get patent protection to commercialize their inventions. So that the investment of the firms will not be wasted due to their right to get patent protection for their inventions.

6. The new technology gives an opportunity to explore new business and sustainable earnings through the use of systematic commercialisation process.

\section{Challenges for Nanotechnology Commercialization}

New inventions based on new technology, usually attract attention due to their ingenuity, but a product must also be useful and compelling, enabling it to be used in everyday life. The objective of the firm is to identify a market for its new products [8]. From a business perspective, the steps to be followed for the successful commercialization of a nanotechnology-based product include market size, market potential, and the economic scenario of the countries and the people who use such products [9]. Common challenges faced by nanotechnology firms are:

(i) Time Lag: The average time delay between research, completion, and commercialization of a nanotechnology product can lie between three to five years [10-11]. The banks and other financial funding agencies, find this time lag to be a major detriment due to the fact of the block of their capital [12].

(ii) Valley of Death: This is the gap between a positive scientific result of a researcher and obtaining supporting funds for commercialization and prototyping of the product [12]. Since the cost of 
commercialization is very high compared to the invention cost of the product, usually, the scientist who invented the product may not have the interest in commercialization, but the firms invested for such research have to spend to encash its business opportunity.

(iii) Lack of infrastructure: Nanotechnology product based research is expensive and requires costly instruments. The lack of infrastructure retards the progress of new product invention.

(iv) Lack of standard for evaluation: A major obstacle for developing nano-products is the lack of standards for evaluation of performance at different stages of research. Because of this, normalizing standards by which nanotechnologies can be evaluated are lacking which affects the patenting process.

(v) Bureaucratic delays: Patent policies take up to thirty-six months to respond to a single application, a serious problem when even a slight delay can be detrimental. Due to lack of a coherent policy on technology transfer from universities to start-up businesses and a considerable red tape must be dealt with for any such transfer using black ocean strategy [8].

(vi) Dearth of funding: Since the research in nanotechnology is capital intensive due to the state-of-the-art instruments requirement, firms faces challenges in obtaining funding. Thus, commercialization of nanotechnology products requires huge investments which small to medium firms cannot be secure easily.

(vii) Lack of trained professionals: The lack of sufficiently trained scientists, engineers, technicians, and researchers in the field is another barrier [12]. This is mostly due to lack of addition of nanoscience and technology in the engineering and science syllabus.

(viii) Pseudo Environmentalist: The speculation in environmental, health and safety issues of nanotechnology-based products, there is much debate about effects of nanotechnology might have on surroundings. Pseudo-environmentalists take this as an opportunity for fighting against the technology and do negative publicity to pressurize the firms to demand ransom.

(ix) Public support: Public support is always favourable due to their expectation towards any emerging technology, including nanotechnology. As a result, firms who invest in new technology to provide better high-tech products to them gets a higher brand image and public sentiments in their favour but small firms and start-ups that currently constitute a major chunk of nanotechnology product firms do not have such advantage [13-18].

(x) Sustainability in the market: The final challenge for the firms is maintaining the sustainability of the commercialized product or service for the longer time to get the return on investment and expected profits through planning and executing proper marketing strategy.

\section{Nanotechnology and Corporate Business Strategy}

Corporate strategy of an organization is a long-term plan to ensure success in its business. The organizations are following various strategies to ensure business sustainability either expanding their business globally, or by adding values to their existing business, or by expanding to new products or services which have potential opportunities in the future market. The various corporate strategies followed by organizations are broadly divided into five categories as Red ocean strategy, Blue ocean strategy, Green ocean strategy, Black ocean strategy, or White ocean mixed strategy as explained below:

(a) Nanotechnology gives the competitive advantage for Red Ocean strategy players [19] by improving their product features using NT research. Since nanotechnology products are comparatively new and rarely available in the market, the competition is proportionately less.

(b) Nanotechnology supports to develop new monopoly products for Blue Ocean strategy players [20] by inventing revolutionary new patented products using NT research. By identifying new applications of existing nanotechnology products or by inventing new avenues of developing innovative products with the patent right, nanotechnology firms can follow blue ocean strategy.

(c) NT supports to develop new sustainable products for Green Ocean strategy players [21] by taking care 
of environmental degradation through NT research. The existing business firms can develop a strategy to improve the features of their products to make them environmental friendly which is the part of their corporate social responsibility. The new firms shall develop processes of manufacturing and the end products to be marketed as environmental friendly by erasing the carbon footprint using nanotechnology.

(d) Nanotechnology supports to develop new sustainable products for White Ocean strategy players [22] by strong collaboration and competition; address multi-stakeholders and responsible development by avoiding any unpredictable danger, threat and risk to living beings through NT research.

(e) Nanotechnology based products have substantial advantages in wars and military operations including weapons and weapon carrier systems so that many firms doing military weapons business use black ocean strategy [23] to get huge orders from bureaucrats and politicians who have the deciding power of purchase.

\section{Conclusion}

Based on research results and publications, it is understood that nanotechnology is going to be the general purpose technology to support and solve major problems of the human beings and the society due to its potential ability to find amicable solutions at micro-level and expanding it to macro-level. The importance of nanotechnology is analyzed by listing advantages, benefits, constraints, and disadvantages in solving social and technological problems in the society. It is found that nanotechnology commercialization is lagging behind due to many reasons and hence failed to follow the expected generations in its growth stages. But as per new predictions, nanotechnology is developing to solve almost all problems of human life by 2050 by reaching the stage of singularity in which growth rate in NT applications become infinite. In this paper, we have developed a commercialization model for nanotechnology products and services and discussed the opportunities, challenges, and possible corporate business strategies for nanotechnology commercialization.

\section{References}

[1] Aithal P. S., and Shubhrajyotsna Aithal. Managing Anticipated Breakthrough Technologies of 21st Century - A Review. International Journal of Research \& Development in Technology and Management Sciences, 2015; 21 (6):112 - 133.

[2] Aithal, P. S., and Shubhrajyotsna Aithal. Ideal Technology Concept \& its Realization Opportunity using Nanotechnology. International Journal of Application or Innovation in Engineering \& Management, 2015; 4 (2): 153-164.

[3] Renn, O., Roco, M. White paper no.2 Nanotechnology risk governance. International Risk Governance Council, Geneva, Switzerland. p.103. 2006.

[4] Aithal P. S., Shailashree V. T., Suresh Kumar P. M. A New ABCD Technique to Analyze Business Models \& Concepts. International Journal of Management, IT and Engineering (IJMIE), 2015; 5(4): $409-423$.

[5] Aithal, P.S. Study on ABCD Analysis Technique for Business Models, Business strategies, Operating Concepts \& Business Systems. International Journal in Management and Social Science, 2016; 4(1): 98-115.

[6] Craig B., Richard M., Grant E., and Darren M., Success factors to a nanotech-enabled whole product, in Nanotechnology Commercialisation edited by Takuya Tsuzuki, Pan Stanford Publishing Pvt. Ltd. p. 171, 2013.

[7] Rogers, E.M. Diffusion of Innovation. The Free Press, NY, 1995.

[8] Mazzola L. Commercializing nanotechnology. Nature Biotechnology, 2003; 21: 1137-43.

[9] Hobson D. W. Commercialization of nanotechnology. Wiley Interdiscip Rev Nanomed Nanobiotechnol, 2009; 1:189-202. 
[10] Beer C, Foldbjerg R, Hayashi Y, Sutherland DS, Autrup H. Toxicity of silver nanoparticles nanoparticle or silver ion? Toxicology Letters. 2012; 208: 286-292.

[11] Patra J.K, Gouda S. Application of nanotechnology in textile engineering: An overview. J Engineering Techn Res, 2013; 5: 104-111.

[12] McNeil R.D, Lowe J, Mastroianni T, Cronin J, Ferk D. Barriers to nanotechnology commercialization. U.S. Department of Commerce Technology Administration, 2007.

[13] Naseri R, Davoodi R. Commercialization of nanotechnology in developing countries, 3rd International Conference on Information and Financial Engineering, Singapore, IACSIT, 2011.

[14] Mazumder S, Sarkar D, Puri I.K. Nanotechnology Commercialization: Prospects in India. J Mater Sci Nanotechnol, 2014; 2(2): 201.

[15] Waitz A, Bokhari W. Nanotechnology commercialization best practices, 2003.

[16] Aithal P. S. and Shubrajyotsna Aithal. Nanotechnological Innovations \& Business Environment for Indian Automobile Sector: A Review. International Journal of Scientific Research and Modern Education, 2016; 1(1): 296-307.

[17] Aithal P.S. and Shubhrajyotsna Aithal. Business Strategy for Nanotechnology based Products \& Services. Journal of Management Sciences and Business Research 2016; 5 (4):139-149.

[18] Aithal P.S. and Shubhrajyotsna Aithal. Nanotechnology Innovations \& Business Opportunities: A Review. International Journal of Management, IT and Engineering 2016; 6 (1): 182-204.

[19] Porter M. E., Competitive Strategy, New York, The Free Press, 1980.

[20] Kim W. C., and Mauborgne R. Blue Ocean Strategy: How to Create Uncontested Market Space and Make the Competition Irrelevant. Harvard Business Review, October, 2004; 71-81.

[21] Silviu M. and Adrian D. T. The Green Ocean Innovation Model. Global Advanced Research Journal of Management and Business Studies 2013; 2(11): 536-541.

[22] Aithal P. S. The concept of Ideal Strategy \& its realization using White Ocean Mixed Strategy. International Journal of Management Sciences and Business Research 2016; 5(4): 171-179.

[23] Aithal P.S., Suresh Kumar P. M. Black Ocean Strategy - A Probe into a New type of Strategy used for Organizational Success. GE International Journal of Management Research, 2015; 3(8): 45 - 65.

\section{Authors' Profiles}

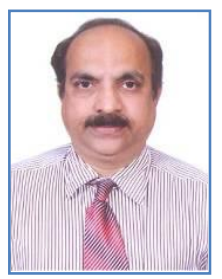

Prof. Dr. P. S. Aithal is belonging to Udupi, India, born on 04/04/1966. He has M.Sc. in Physics from Mangalore University, India, M.Sc. in E-Business from Manipal University, India, M.Tech. in Information Technology from Karnataka University, India, Ph.D. in Physics from Mangalore University, India, and Ph.D. in Management from Manipal University, India. His major fields of study are the characterization of nonlinear optical materials, optical solutions, e-commerce and mobile business. He has two years postdoctoral research experience at Physical Research Laboratory, Ahmedabad, India and one-year postdoctoral research experience at CREOL, University of Central Florida, USA, in the field of Characterization of nonlinear optical materials. He has about 22 years teaching experience both at UG and PG level in Electronics, Computer Science and Business management. Currently, he is working as PRINCIPAL at Srinivas Institute of Management Studies, Mangalore, India. He has published about 100 research papers in peer-reviewed journals and two textbooks on physics and Electronics for Engineering students. He has the research interest in Nonlinear optical absorption, Optical Phase Conjugation, Photorefractive materials, e-business, m-business, ideal business, and nanotechnology business Opportunities. Dr. Aithal is the member of World Productivity Council, U.K., the member of Strategic Management Forum, India, the member of Photonics Society of India, CUSAT, Cochin, senior member of IEDRC.org, Singapore. 
Mrs. Shubhrajyotsna Aithal is belonging to Mangalore, India. She has M.Sc. in Material Science from Mangalore University, India, M.Sc. in Chemistry from Kuvempu University, India, and M.Phil. in Chemistry, Vinayaka University, India. Presently she is doing her Ph.D. in the field of Characterization of nonlinear optical materials in Rayalaseema University, India. She has 12 years teaching experience in teaching Chemistry for undergraduate students. Presently she is working as Senior Lecturer in Chemistry at Srinivas College, Pandeshwar, Mangalore, Karnataka State, India. Her research interests are in nonlinear absorption, nonlinear refraction, optical limiting and generation of Phase Conjugated signal in dye-doped polymers. Mrs. Aithal has published 12 papers in refereed journals in the field of characterization of nonlinear optical materials and nanotechnology applications.

How to cite this paper: P. Sreeramana Aithal, Shubhrajyotsna Aithal,"Nanotechnology Innovations and Commercialization-Opportunities, Challenges \& Reasons for Delay", International Journal of Engineering and Manufacturing(IJEM), Vol.6, No.6, pp.15-25, 2016.DOI: 10.5815/ijem.2016.06.02 